Research Paper

\title{
Carbon-ion radiotherapy for cholangiocarcinoma: a multi- institutional study by and the Japan carbon-ion radiation oncology study group (J-CROS)
}

\author{
Goro Kasuya ${ }^{1}$, Kazuki Terashima², Kei Shibuya ${ }^{3}$, Shingo Toyama ${ }^{4}$, Daniel K. Ebner ${ }^{1,5}$, \\ Hiroshi Tsuji ${ }^{1}$, Tomoaki Okimoto², Tatsuya Ohno ${ }^{3}$, Yoshiyuki Shioyama6, Takashi \\ Nakano ${ }^{1}$, Tadashi Kamada ${ }^{1}$ and the Japan Carbon-Ion Radiation Oncology Study \\ Group \\ ${ }^{1}$ QST Hospital (Former Hospital of the National Institute of Radiological Sciences), National Institutes for Quantum and \\ Radiological Science and Technology, Chiba, Japan \\ ${ }^{2}$ Department of Radiology, Hyogo Ion Beam Medical Center, Tatsuno, Japan \\ ${ }^{3}$ Gunma University Heavy Ion Medical Center, Maebashi, Japan \\ ${ }^{4}$ Ion Beam Therapy Center, SAGA-HIMAT Foundation, Tosu, Japan \\ ${ }^{5}$ Harvard TH Chan School of Public Health, Boston, MA, USA \\ ${ }^{6}$ Department of Radiology, Kyushu University, Hakata, Japan \\ Correspondence to: Goro Kasuya, email: kasuya.goro@qst.go.jp \\ Keywords: carbon-ion radiotherapy; radiation; cholangiocarcinoma; adverse event; survival \\ Received: March 06, $2019 \quad$ Accepted: June 05, $2019 \quad$ Published: July 09, 2019 \\ Copyright: Kasuya et al. This is an open-access article distributed under the terms of the Creative Commons Attribution License \\ 3.0 (CC BY 3.0), which permits unrestricted use, distribution, and reproduction in any medium, provided the original author and \\ source are credited.
}

\section{ABSTRACT}

To evaluate the safety and efficacy of carbon-ion radiotherapy (CIRT) for cholangiocarcinoma via a multicenter retrospective study. Clinical data were collected from patients with cholangiocarcinoma who had received CIRT at one of four treating institutions in Japan. Of 56 eligible patients, none received surgery for cholangiocarcinoma before or after CIRT. The primary endpoint was overall survival (OS). Based on the tumor site, the 56 cases were categorized as intrahepatic cholangiocarcinoma (IHC) $(n=27)$ or perihilar cholangiocarcinoma (PHC) $(n=29)$. In all patients, the median tumor size was 37 (range, 15-110) $\mathrm{mm}$, and the most commonly prescribed dose was 76 Gy (relative biological effectiveness) in 20 fractions. The median survival was 14.8 (range, 2.1-129.2) months, and the 1- and 2-year OS rates were $69.7 \%$ and $40.9 \%$, respectively. The median survival times of the patients with IHC and those with PHC were 23.8 and 12.6 months, respectively. Both univariate and multivariate analyses revealed that cholangitis pre-CIRT and Child-Pugh class B were significant prognostic factors for an unfavorable OS. Of four patients who died of liver failure, one with IHC was suspected to have radiationinduced liver disease because of newly developed ascites, and died at 4.3 months post-CIRT. Grade 3 CIRT-related bile duct stenosis was observed in one IHC case. No other CIRT-related severe adverse events, including gastrointestinal events, were observed. These results suggest that CIRT yields relatively favorable treatment outcomes, especially for patients with IHC, and acceptable toxicities were observed in patients with cholangiocarcinoma who did not receive surgery. 


\section{INTRODUCTION}

Cholangiocarcinoma is relatively uncommon, accounting for only $15 \%$ of hepatic malignancies [1]. Standard radical therapy involves surgery, although few patients are candidates for curative surgical resection at the time of presentation [2]. Although the typical standard treatment for inoperable cholangiocarcinoma is chemotherapy, the median survival time (MST) even after combined chemotherapy, including gemcitabine and cisplatin, is reported to be at most approximately 1 year $[3,4]$. Conventionally fractionated radiotherapy has been suggested as a combination tactic for unresectable cholangiocarcinoma, with and without chemotherapy, for potential prolongation of survival; however, the prognoses remain poor according to several retrospective studies [5, 6]. Recently, stereotactic radiotherapy (SBRT) has enabled delivery of higher-dose irradiation to the tumor than conventional X-ray radiotherapy, and the effectiveness of these novel techniques is promising $[7,8]$. However, radiotherapy-related severe adverse events, particularly duodenal or gastric ulcers, are reported to occur $10-20 \%$ of the time [9].

Carbon-ion radiotherapy (CIRT) offers a higher linear energy transfer and subsequently greater relative biological effectiveness (RBE) compared with photons. Moreover, the Bragg-peak and limited lateral scattering of the beam offer a superior dose delivery in comparison with photon irradiation, allowing increased dose delivery to the tumor while reducing the dose to healthy tissue [10-12]. However, there is only one study on CIRT for cholangiocarcinoma, which was based on a small cohort from a single institution [13]. As such, the efficacy and safety of CIRT for cholangiocarcinoma are poorly understood.

We conducted a retrospective multicenter study to evaluate the clinical outcomes of CIRT for cholangiocarcinoma, referred to as Japan Carbon-Ion Radiation Oncology Study Group (J-CROS 1703). The purpose of this study was to evaluate the efficacy and safety of CIRT for the treatment of cholangiocarcinoma.

\section{RESULTS}

The patient, tumor, and treatment characteristics of all 56 eligible patients with cholangiocarcinoma comprising 27 patients with intrahepatic cholangiocarcinoma (IHC) and 29 patients with perihilar cholangiocarcinoma (PHC), are shown in Table 1. All patients were restaged according to the $7^{\text {th }}$ edition of the Tumor-Node-Metastasis staging system (International Union Against Cancer, 2009). The median tumor size was 37 (range, 15-110) mm. Biopsy was performed in 35 patients (63\%), all of whom were diagnosed with adenocarcinoma except 2 patients who were diagnosed with mixed hepatocellular carcinoma/cholangiocarcinoma. The remaining 21 patients were diagnosed by imaging (dynamic contrast enhanced computed tomography and/ or magnetic resonance imaging) as well as detection of elevated tumor markers (CA19-9 and/or CEA). The most commonly prescribed CIRT dose was 76 Gy (RBE) in 20 fractions (biological effective dose [BED] of 105 when $\alpha / \beta=10$ was applied). Thirteen patients (23\%) were treated previously with chemotherapy, one patient with concurrent chemotherapy, and one patient with radiofrequency ablation. However, all tumors that were treated with other therapies had progressed prior to CIRT. No patient received surgical treatment for cholangiocarcinoma in this study.

\section{Treatment effect}

The rate of completion of prescribed CIRT treatment course was 98\% (55/56); the one patient with PHC who did not complete the course was required to undergo stent replacement due to worsening cholangitis after delivery of 24 of 25 fractions. The median follow-up time was 10.6 (range 1.6-129.2) months; seven patients (13\%) were lost to follow-up. Sixteen patients (28\%) experienced local recurrence. The 1- and 2-year LC rates were 79.4\% (95\% confidence interval [CI], 62.7-89.2\%) and 58.2\% (95\% CI, 37.7-74.0\%), respectively. Distant failure was noted in 19 patients (34\%), including 3 patients who also experienced local failure. The median time to progression for all 56 patients was 9.2 months, with 1- and 2-year PFS rates of $54.1 \%(95 \% \mathrm{CI}, 38.4-67.4 \%)$ and $32.3 \%(95 \%$ CI, 18.0-47.6\%), respectively. Of the 32 patients who experienced recurrence after CIRT (local failure only, $n=13$; distant failure only, $n=16$; local plus distant failure, $n=3), 20(65 \%)$ selected best supportive care for treatment. The remaining 12 patients (35\%) chose the following salvage treatments: chemotherapy $(n=10)$, radiofrequency ablation $(n=1)$, and repeat CIRT $(n=1)$, respectively.

By the end of follow-up, 15 patients (27\%) were still alive. The MST for all 56 patients was 14.8 (range, 2.1-129) months. The 1- and 2-year OS rates were $69.7 \%$ (95\% CI, $55.3-80.2 \%$ ) and $40.9 \%$ (95\% CI, 26.8-54.4\%), respectively. Figure 1 shows Kaplan-Meier curves for the OS of the IHC $(n=27)$ and PHC $(n=29)$ patients. The 1- and 2-year OS rates and MST were $77.8 \%$ (95\% CI, 57.1-89.3\%), 53.4\% (95\% CI, 32.6-70.4\%), and 23.8 months for the patients with IHC versus $61.1 \%$ (95\% CI, 39.7-76.9\%), $26.3 \%$ (95\% CI, $10.1-45.9 \%$ ), and 12.6 months for the patients with PHC, respectively (log-rank, $\mathrm{p}=0.018$ ). After excluding the 7 patients lost to follow-up from the analysis, the 1- and 2-year OS rates and MST of the remaining 49 patients were $67.3 \%$ (95\% CI, 52.3-78.6\%), and 39.2\% (95\% CI, 25.4-52.7\%), and 17.5 months, respectively. The MSTs of the patients with $\operatorname{IHC}(n=26)$ and PHC $(n=23)$ were 24.7 and 13.6 months, respectively (log-rank, $\mathrm{p}=0.011$ ). The distributions of the causes of death and local/distant failure in all patients and according to the tumor site (PHC vs. IHC) are presented in Table 3.

Both the univariate and multivariate analyses revealed that cholangitis pre-CIRT and Child-Pugh class $\mathrm{B}$ were significant prognostic factors for an unfavorable 
Table 1: Patient, tumor, and treatment characteristics

\begin{tabular}{|c|c|c|c|c|c|}
\hline Factor & & $\begin{array}{c}\text { Total } \\
{[n=56](\%)}\end{array}$ & $\begin{array}{c}\text { Intrahepatic } \\
\text { cholangiocarcinoma } \\
{[n=27](\%)}\end{array}$ & $\begin{array}{c}\text { Perihilar } \\
\text { cholangiocarcinoma } \\
{[n=29](\%)}\end{array}$ & $p$ \\
\hline Age, years & Median, [range] & $74[43-87]$ & $75[57-87]$ & $71[43-86]$ & $0.225^{\S}$ \\
\hline \multirow[t]{2}{*}{ Sex } & Male & $38(68)$ & $19(70)$ & $19(66)$ & $0.698^{*}$ \\
\hline & Female & $18(32)$ & $8(30)$ & $10(34)$ & \\
\hline \multirow[t]{2}{*}{ Operability } & Operable & $10(18)$ & $5(19)$ & $5(17)$ & $0.587^{\natural}$ \\
\hline & Inoperable & $46(82)$ & $22(81)$ & $24(83)$ & \\
\hline \multirow[t]{2}{*}{ Performance status } & $0 / 1$ & $52(93)$ & $26(96)$ & $26(90)$ & $0.333^{\circ}$ \\
\hline & 2 & $4(7)$ & $1(4)$ & $3(10)$ & \\
\hline \multirow[t]{2}{*}{ Child-Pugh class } & A & $52(93)$ & $26(96)$ & $26(90)$ & $0.333^{\circ}$ \\
\hline & B & $4(7)$ & $1(4)$ & $3(10)$ & \\
\hline \multirow{2}{*}{$\begin{array}{l}\text { Prior therapy for } \\
\text { cholangiocarcinoma }\end{array}$} & Yes & $13(23)$ & $6(22)$ & $7(24)$ & $0.865^{*}$ \\
\hline & No & $43(77)$ & $21(78)$ & $22(76)$ & \\
\hline \multirow[t]{2}{*}{ Cholangitis pre-CIRT } & Yes & $11(20)$ & $0(0)$ & $11(38)$ & $<0.001^{\pi}$ \\
\hline & No & $45(80)$ & $27(100)$ & $18(62)$ & \\
\hline \multirow{2}{*}{$\begin{array}{l}\text { Biliary stenosis pre- } \\
\text { CIRT }\end{array}$} & Yes & $27(48)$ & $0(0)$ & $27(93)$ & $<0.001^{\pi}$ \\
\hline & No & $29(52)$ & $27(100)$ & $2(7)$ & \\
\hline \multirow{2}{*}{$\begin{array}{l}\text { Stent treatment for } \\
\text { biliary stenosis pre- } \\
\text { CIRT }\end{array}$} & Yes & $24(43)$ & $0(0)$ & $24(83)$ & $<0.001^{\rrbracket}$ \\
\hline & No & $32(57)$ & $27(100)$ & $5(17)$ & \\
\hline \multirow[t]{2}{*}{ Diagnosis } & Pathological & $35(63)$ & $17(63)$ & $18(62)$ & $0.945^{*}$ \\
\hline & Imaging + tumor markers & $21(37)$ & $10(37)$ & $11(38)$ & \\
\hline \multirow[t]{7}{*}{ TNM classification } & T1N0M0 & $13(23)$ & $9(33)$ & $4(14)$ & $<0.001^{\pi}$ \\
\hline & T2aN0M0 & $15(27)$ & $12(44)$ & $3(10)$ & \\
\hline & T2bN0M0 & $2(4)$ & $1(4)$ & $1(3)$ & \\
\hline & T3N0M0 & $9(16)$ & $2(7)$ & $7(24)$ & \\
\hline & T4N0M0 & $13(23)$ & $1(4)$ & $12(42)$ & \\
\hline & T2aN1M0 & $1(2)$ & $1(4)$ & 0 & \\
\hline & T4N1M0 & $3(5)$ & $1(4)$ & $2(7)$ & \\
\hline \multirow[t]{3}{*}{ Tumor size, mm } & Median [range] & $37[15-110]$ & $43[25-110]$ & 30 [15-99] & $0.005^{\S}$ \\
\hline & $<37 \mathrm{~mm}$ & $28(50)$ & $14(52)$ & $14(48)$ & $0.789^{*}$ \\
\hline & $\geq 37 \mathrm{~mm}$ & $28(50)$ & $13(48)$ & $15(52)$ & \\
\hline \multirow[t]{2}{*}{ Tumor number } & Single & $50(89)$ & $22(81)$ & $28(97)$ & $0.081^{\pi}$ \\
\hline & Multiple & $6(11)$ & $5(19)$ & $1(3)$ & \\
\hline $\mathrm{CEA}, \mathrm{mg} / \mathrm{ml}$ & Median [range] & $4.4[0.7-51.2]$ & $2.6[0.7-44.0]$ & $2.3[1.1-51.2]$ & $0.052^{\S}$ \\
\hline CA19-9, U/ml & Median [range] & $124[0-7614]$ & $190[0-7614]$ & $94.9[0-5540]$ & $0.737^{\S}$ \\
\hline \multirow{9}{*}{$\begin{array}{l}\text { Dose/fractionation } \\
\text { [BED10] }\end{array}$} & $52.8 \mathrm{~Gy}(\mathrm{RBE}) / 12$ fr. [76] & $1(2)$ & 0 & $1(3)$ & $0.001^{\pi}$ \\
\hline & 52.8 Gy (RBE)/4 fr. [122] & $5(9)$ & $5(19)$ & 0 & \\
\hline & 60 Gy (RBE)/12 fr. [90] & $7(13)$ & $6(22)$ & $1(3)$ & \\
\hline & 60 Gy (RBE)/4 fr. [150] & $5(9)$ & $4(15)$ & $1(3)$ & \\
\hline & $64.8 \mathrm{~Gy}(\mathrm{RBE}) / 24$ fr. [82] & $1(2)$ & 0 & $1(3)$ & \\
\hline & 65 Gy (RBE)/26 fr. [81] & $1(2)$ & 0 & $1(3)$ & \\
\hline & 66 Gy (RBE)/10 fr. [110] & $1(2)$ & $1(4)$ & 0 & \\
\hline & 70.2 Gy (RBE)/26 fr. [89] & $13(23)$ & $4(15)$ & $9(31)$ & \\
\hline & $76 \mathrm{~Gy}(\mathrm{RBE}) / 20$ fr. $[105]$ & $22(39)$ & $7(26)$ & $15(51)$ & \\
\hline
\end{tabular}

${ }^{*}$ Chi-square test, ${ }^{\circledR}$ Mann-Whitney $U$ test, ${ }^{\circledR}$ Fisher's exact test.

Abbreviations: HBV: hepatitis B virus, HCV: hepatitis C virus, BED10, biological effective dose when $\alpha / \beta=10$ is applied, Gy: gray, RBE: relative biological effectiveness, CEA: carcinoembryonic antigen, CA19-9: carbohydrate antigen 19-9. 
OS (Table 2). On the other hand, no prognostic factors among those evaluated were significantly associated with LC or PFS (Supplementary Table 1).

\section{Adverse events}

Table 4 shows the details of the four patients who died of liver failure. Of these, one patient with IHC (\#1 in Table 4) was judged to have CIRT-induced liver disease, as the patient first developed ascites following CIRT, and ascites cytology was negative. He died of liver failure at 4.3 months post-CIRT. Of the remaining three patients, one with IHC (\#2 in Table 4) experienced deteriorating liver function due to IHC pre-CIRT and died 14.5 months post-CIRT, and two with PHC (\#3 and \#4 in Table 4) had persistent cholangitis or biliary stenosis pre-CIRT and died at 7.2 and 22.3 months post-CIRT, respectively. It was difficult to determine the role of CIRT in the liver failure found in cases \#2-4 in Table 4. In addition, there was one grade 3 CIRT-related adverse event of bile duct stenosis, in an IHC case. No other CIRT-related grade 3 or more severe adverse events were observed, including gastrointestinal events such as nausea, vomiting, bleeding, ulcers, or stricture. The relationships between severe adverse events and several factors were analyzed on univariate analysis (Supplementary Table 2), and cholangitis pre-CIRT was the only factor found to be significantly associated with severe adverse events after CIRT $(p=0.047)$.

\section{DISCUSSION}

The 56 patients with cholangiocarcinoma treated with CIRT, of whom more than $80 \%$ were inoperable with comorbidities or advanced tumors as judged by surgeons, demonstrated relatively favorable treatment outcomes, especially for the patients with IHC, without undergoing surgical resection. This study revealed a MST of 14.8 months for all 56 patients, 23.8 months for the 27 patients with IHC, and 12.6 months for the 29 patients with PHC after CIRT for cholangiocarcinoma. To the best of our knowledge, there has been no multicenter study on cholangiocarcinoma post-CIRT.

Among the patients with PHC, two died of liver failure, which was caused by bile duct stenosis $(n=1)$ or cholangitis due to tumor invasion $(n=1)$, and three died of sepsis caused by cholangitis (these three causes are indicated in italics in Table 3). Liver failure or sepsis following bile duct stenosis or cholangitis can occur during the natural course of PHC [2], which can confound evaluation of the treatment effects in PHC after CIRT. Nonetheless, the OS was significantly poorer among patients with PHC compared with those with IHC in the present study. Bile duct stenosis and cholangitis pre-CIRT were observed in the patients with $\mathrm{PHC}$, and remain even after CIRT, which may affect prognosis directly. Such features of PHC may explain why cholangitis pre-CIRT was found to be significant factor for OS in this study.

Furthermore, OS was significantly poorer among patients with Child-Pugh class B compared with class A, although this result was based on only four patients with Child-Pugh class B in this cohort; however, a relationship between Child-Pugh class B and poor survival is supported by a study on CIRT for hepatocellular carcinoma [14]. Close monitoring of patients with Child-Pugh class B cholangiocarcinoma undergoing CIRT will be needed.

Table 5 presents a comparison of our results with those from other trials using photon or proton radiotherapy administered with or without chemotherapy. The OS

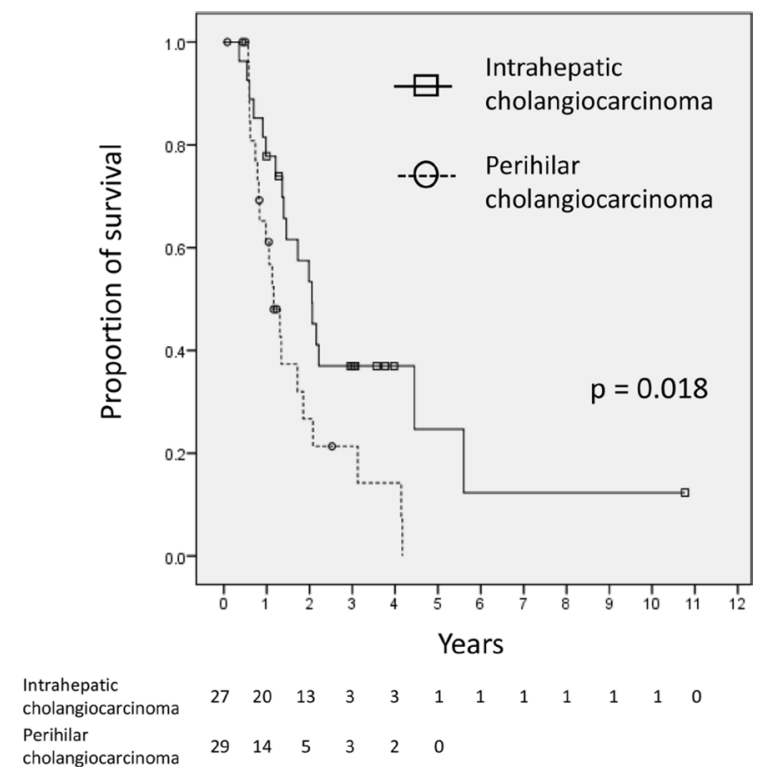

Figure 1: Kaplan-Meier curves of the OS rates of patients with intrahepatic cholangiocarcinoma $(n=27)$ and perihilar cholangiocarcinoma $(\boldsymbol{n}=\mathbf{2 9})$. There was a significant difference between the two survival curves $(p=0.018)$. 


\begin{tabular}{|c|c|c|c|c|c|c|c|c|c|}
\hline & & \multirow{2}{*}{$\begin{array}{l}\text { No. of } \\
\text { patients }\end{array}$} & \multicolumn{2}{|c|}{ Univariate analyses } & \multicolumn{5}{|c|}{ Multivariate analyses } \\
\hline & & & $\begin{array}{l}1-\text { year } \\
\text { OS\% }\end{array}$ & $\mathbf{p}$ & HR & $95 \% \mathrm{C}$ & & & $\mathbf{p}$ \\
\hline \multirow[t]{2}{*}{ Age, years } & $<76$ & 33 & 71.0 & 0.855 & & & & & \\
\hline & $>76$ & 23 & 67.8 & & & & & & \\
\hline \multirow[t]{2}{*}{ Sex } & Male & 38 & 72.1 & 0.917 & & & & & \\
\hline & Female & 18 & 64.7 & & & & & & \\
\hline \multirow[t]{2}{*}{ Operable } & yes & 10 & 60.0 & 0.411 & & & & & \\
\hline & no & 46 & 71.8 & & & & & & \\
\hline \multirow[t]{2}{*}{ Performance status } & $0 / 1$ & 52 & 69.8 & 0.389 & & & & & \\
\hline & 2 & 4 & 66.7 & & & & & & \\
\hline \multirow[t]{2}{*}{ Child-Pugh class } & A & 52 & 73.4 & 0.014 & Reference & & & & \\
\hline & $\mathrm{B}$ & 4 & 25.0 & & 4.079 & 1.342 & - & 12.400 & 0.013 \\
\hline \multirow{2}{*}{$\begin{array}{l}\text { Prior therapy for } \\
\text { cholangiocarcinoma }\end{array}$} & yes & 13 & 76.9 & 0.177 & & & & & \\
\hline & no & 43 & 67.3 & & & & & & \\
\hline \multirow{2}{*}{ Cholangitis pre-CIRT } & yes & 11 & 60.0 & 0.012 & 3.091 & 1.180 & - & 8.100 & 0.022 \\
\hline & no & 45 & 71.9 & & Reference & & & & \\
\hline \multirow{2}{*}{$\begin{array}{l}\text { Biliary stenosis pre- } \\
\text { CIRT }\end{array}$} & yes & 27 & 63.5 & 0.035 & 0.416 & 0.072 & - & 2.396 & 0.326 \\
\hline & no & 29 & 75.1 & & Reference & & & & \\
\hline \multirow{2}{*}{$\begin{array}{l}\text { Stent treatment for } \\
\text { biliary stenosis pre- } \\
\text { CIRT }\end{array}$} & yes & 24 & 63.0 & 0.016 & 3.736 & 0.745 & - & 18.730 & 0.109 \\
\hline & no & 32 & 78.4 & & Reference & & & & \\
\hline \multirow[t]{2}{*}{ Diagnostic method } & Imaging & 21 & 68.4 & 0.871 & & & & & \\
\hline & Pathological & 35 & 70.2 & & & & & & \\
\hline \multirow[t]{2}{*}{ TNM stage } & T1-2N0M0 & 39 & 75.1 & 0.133 & & & & & \\
\hline & Advanced & 17 & 58.2 & & & & & & \\
\hline \multirow[t]{2}{*}{ Tumor size } & $<37 \mathrm{~mm}$ & 28 & 65.3 & 0.933 & & & & & \\
\hline & $>37 \mathrm{~mm}$ & 28 & 74.1 & & & & & & \\
\hline \multirow[t]{2}{*}{ Tumor number } & Single & 50 & 68.5 & 0.640 & & & & & \\
\hline & Multiple & 6 & 80.0 & & & & & & \\
\hline \multirow[t]{2}{*}{ CA19-9 } & $<200$ & 33 & 78.1 & 0.334 & & & & & \\
\hline & $>200$ & 23 & 56.5 & & & & & & \\
\hline \multirow[t]{2}{*}{ CEA } & $<10$ & 48 & 71.6 & 0.868 & & & & & \\
\hline & $>10$ & 8 & 57.1 & & & & & & \\
\hline \multirow[t]{2}{*}{ Total BED10 } & $<105$ & 23 & 75.9 & 0.482 & & & & & \\
\hline & $>105$ & 33 & 65.6 & & & & & & \\
\hline \multirow[t]{2}{*}{ Fraction number } & $<20$ & 20 & 23.8 & 0.234 & & & & & \\
\hline & $>20$ & 36 & 16.1 & & & & & & \\
\hline
\end{tabular}

Abbreviations: HR: hazard ratio; CI: confidence interval; CA19-9: carbohydrate antigen 19-9; CEA: carcinoembryonic antigen; BED10: biological effective dose when $\alpha / \beta=10$ is applied. 


\begin{tabular}{|c|c|c|c|}
\hline & $\begin{array}{l}\text { All patients } \\
{[\mathrm{n}=\mathbf{5 6}]}\end{array}$ & $\begin{array}{c}\text { Intrahepatic } \\
\text { cholangiocarcinoma } \\
{[\mathbf{n}=\mathbf{2 7}]} \\
\end{array}$ & $\begin{array}{c}\text { Perihilar } \\
\text { cholangiocarcinoma } \\
{[n=29]} \\
\end{array}$ \\
\hline Alive patients, $n(\%)$ & $15(27 \%)$ & $8(30 \%)$ & $7(24 \%)$ \\
\hline Patients lost to follow up & $7(13 \%)$ & $1(4 \%)$ & $6(21 \%)$ \\
\hline Total deaths, $n(\%)$ & $41(73 \%)$ & $19(70 \%)$ & $22(76 \%)$ \\
\hline Cholangiocarcinoma-specific death & 31 & 14 & 17 \\
\hline $\begin{array}{l}{ }^{\# 1} \text { Liver failure due to CIRT (newly } \\
\text { developed ascites) }\end{array}$ & 1 & 1 & 0 \\
\hline $\begin{array}{l}{ }^{\# 2} \text { Liver failure due to persistent poor liver } \\
\text { function }\end{array}$ & 1 & 1 & 0 \\
\hline${ }^{\# 3}$ Liver failure due to cholangitis & 1 & 0 & 1 \\
\hline${ }^{\sharp 4}$ Liver failure due to biliary duct stenosis & 1 & 0 & 1 \\
\hline Sepsis due to cholangitis & 3 & 0 & 3 \\
\hline $\begin{array}{l}\text { Interstitial pneumonia due to } \\
\text { chemotherapy }\end{array}$ & 1 & 1 & 0 \\
\hline Cholangitis due to gallstones & 1 & 1 & 0 \\
\hline Senility & 1 & 1 & 0 \\
\hline Metastasis, n (\%) & $19(34 \%)$ & $10(37 \%)$ & $9(31 \%)$ \\
\hline Liver (only) & 9 & 6 & 3 \\
\hline Lung (only) & 1 & 1 & 0 \\
\hline Lymph node (only) & 2 & 1 & 1 \\
\hline Peritoneum (only) & 2 & 0 & 2 \\
\hline Liver + lung & 1 & 0 & 1 \\
\hline Liver + lymph node & 1 & 1 & 0 \\
\hline Liver + peritoneum & 1 & 0 & 1 \\
\hline Liver + lung + lymph node & 2 & 1 & 1 \\
\hline Local recurrence, $n(\%)$ & $16(29 \%)$ & $7(26 \%)$ & $9(31 \%)$ \\
\hline
\end{tabular}

Abbreviations: CIRT: carbon-ion radiotherapy

\#1-\#4, corresponding to cases \#1-4 listed in Table 4.

The causes listed in italics were observed exclusively among the perihilar cholangiocarcinoma patients.

rates and MST of the present study are comparable with those in previous reports on proton therapy or SBRT; CIRT may also be a promising therapy for patients with cholangiocarcinoma who cannot undergo surgery.

Nevertheless, the treatment outcomes were inadequate in our study, as the distant and local failure rates were $34 \%$ and $29 \%$, respectively (Table 3 ), likely contributing to the poor survival. Regarding the CTV margin, $\mathrm{Bi}$ et al. reported pathological microinvasions 0.4$8 \mathrm{~mm}$ from the gross tumor in IHC cases [15], suggesting that a CTV margin of $10 \mathrm{~mm}$ is sufficient in most cases. However, the actual CTV margin in some cases of this study was less (median $4 \mathrm{~mm}$; range $0-10 \mathrm{~mm}$ ) to avoid adjacent organs at risk, which may have affected the treatment outcomes reported here. In the present study, only one patient received concurrent chemotherapy. By comparison, in a conventional radiotherapy series, OS was significantly improved when treatment included concurrent chemotherapy compared with RT alone [6]. These results suggest that CIRT combined with concurrent chemotherapy may be a reasonable treatment strategy for improving outcomes in patients with unresectable cholangiocarcinoma. However, since the safety of the combined treatment is unknown, a prospective study is required.

Concerning adverse events, four patients died of liver failure (Table 4). One of these was judged to be CIRT-related liver failure due to newly developed ascites without disease recurrence post-CIRT, although transcatheter arterial chemoembolization was performed for another lesion 2 months before CIRT and may have played a role. The remaining three liver failure cases had low liver function with a high indocyanine green retention rate at 15 minutes or biliary symptoms such as cholangitis or bile duct stenosis, due to progression 
Table 4: Four cases of death caused by liver failure after carbon-ion radiotherapy

\begin{tabular}{|c|c|c|c|c|c|c|c|c|c|}
\hline \# & $\begin{array}{l}\text { Age, } \\
\text { years }\end{array}$ & $\mathbf{M} / \mathbf{F}$ & $\begin{array}{l}\text { Pre-CIRT } \\
\text { condition }\end{array}$ & $\begin{array}{l}\text { Maximum } \\
\text { tumor } \\
\text { size, } \mathrm{mm}\end{array}$ & $\begin{array}{c}\text { Dose } \\
\text { Gy } \\
\text { (RBE) }\end{array}$ & Fr & $\begin{array}{l}\text { Tumor } \\
\text { site }\end{array}$ & $\begin{array}{c}\text { Symptoms post- } \\
\text { CIRT }\end{array}$ & $\begin{array}{l}\text { Time to } \\
\text { death, } \\
\text { months }\end{array}$ \\
\hline 1 & 77 & M & $\begin{array}{l}\text { TACE performed } 2 \\
\text { months pre-CIRT } \\
\text { for another lesion }\end{array}$ & 33 & 76 & 20 & $\mathrm{IHC}$ & $\begin{array}{c}\text { Newly developed } \\
\text { ascites }\end{array}$ & 4.3 \\
\hline 2 & 69 & $\mathrm{~F}$ & ICG R 15 of $44 \%$ & 55 & 52.8 & 4 & $\mathrm{IHC}$ & $\begin{array}{l}\text { Continuous gradual } \\
\text { deterioration of liver } \\
\text { function }\end{array}$ & 14.5 \\
\hline 3 & 76 & $\mathrm{~F}$ & $\begin{array}{l}\text { ERBD required } \\
\text { for recurring } \\
\text { cholangitis }\end{array}$ & 30 & 70.2 & 26 & PHC & $\begin{array}{l}\text { Continuous } \\
\text { cholangitis }\end{array}$ & 7.2 \\
\hline 4 & 86 & M & $\begin{array}{l}\text { ERBD required for } \\
\text { biliary duct stenosis } \\
\text { and jaundice }\end{array}$ & 15 & 70.2 & 26 & $\mathrm{PHC}$ & $\begin{array}{c}\text { Continuous biliary } \\
\text { stenosis }\end{array}$ & 22.3 \\
\hline
\end{tabular}

Abbreviations: M: male; F: female; Gy: gray; RBE: relative biological effectiveness; CIRT: carbon-ion radiotherapy; TACE: transcatheter arterial chemoembolization; IHC: intrahepatic cholangiocarcinoma; ICG R15: indocyanine green retention rate at 15 minutes; ERBD: endoscopic retrograde biliary drainage; PHC: perihilar cholangiocarcinoma

of their tumor prior to CIRT. Therefore, it is difficult to determine whether three liver failure cases are related to CIRT. In addition, bile duct stricture was observed in one patient with IHC as a CIRT-related severe adverse event. However, no gastrointestinal severe adverse events were noted in this study, which may be due to the highly conformal nature of the dose distribution of CIRT compared with photon radiotherapy, including SBRT $[8$, 16]. Therefore, the overall safety of CIRT is generally acceptable. Caution should be used in patients who experience cholangitis pre-CIRT, considering the potential for severe adverse events identified in this study.

There were limitations to this study. First, this study was retrospectively conducted in a limited number of patients. Second, several dose and fractionation regimens were included, with a large BED range from 76 (52.8 Gy $[\mathrm{RBE}] / 12$ fractions) to 150 (60 Gy [RBE]/4 fractions). Standardization of the treatment regimen will be needed for efficacy evaluation in large-scale future studies. Third, there was a relatively high rate of lost to follow-up cases $(13 \%)$, and salvage therapy was performed in 12 patients who experienced recurrence, which might have affected the results of this study. Fourth, this study did not include cases of distal extrahepatic cholangiocarcinoma of the bile duct; therefore, the safety and efficacy of CIRT for distal ductal disease are still unknown. Fifth, the median follow-up period was too short to evaluate the long-term safety and efficacy of CIRT. Despite the limitations, this multicenter study is the largest analysis of CIRT for cholangiocarcinoma to date.

In conclusion, this multicenter study in Japan showed promising efficacy and safety for CIRT in patients with cholangiocarcinoma who had not undergone surgery including inoperable cases.

\section{MATERIALS AND METHODS}

\section{Study design}

In December 2018, the data of patients with cholangiocarcinoma who were treated with CIRT between 2005 and 2016 were analyzed retrospectively in J-CROS 1703 (UMIN 000035565). Overall survival (OS) was the primary endpoint, whereas local control (LC), time to progression, progression-free survival (PFS), completion rate of the prescribed CIRT treatment course, and evaluation of adverse events were the secondary endpoints.

Seventy-five patients with cholangiocarcinoma were treated with CIRT at Hyogo Ion Medical Center (Tatsuno, Japan), Hospital of the National Institute of Radiological Sciences (Chiba, Japan), Gunma University Heavy Ion Medical Center (Maebashi Japan), and SAGA HIMAT Foundation Ion Beam Therapy Center (Tosu, Japan) between 2005 and 2016. This multicenter retrospective study was approved by institutional review board of each participating institution. The protocol was performed in accordance with the Declaration of Helsinki [17].

\section{Eligibility}

The inclusion criteria for entry into this study were as follows: 1) biopsy-proven cholangiocarcinoma, or a definitive diagnosis by dynamic contrast-enhanced computed tomography/magnetic resonance imaging studies together with elevated tumor markers (CA19-9 and/or CEA), 2) all lesions, including the primary tumor, daughter nodule, and lymph node metastasis, were treated in a single radiation field, 3) a measurable lesion, 4) no metastasis to other organs, 5) absence of active double cancers other 
Table 5. Comparison of survival outcomes between the present study, and previous studies of radiotherapy

\begin{tabular}{lcccccc}
\hline Treatment, Author & Year & $n$ & $\begin{array}{c}\text { Median total } \\
\text { dose }[G y \text { or } \\
\text { Gy(RBE)] }\end{array}$ & $\begin{array}{c}\text { Median } \\
\text { fraction }\end{array}$ & $\begin{array}{c}\text { Median } \\
\text { BED10 }\end{array}$ & $\begin{array}{c}\text { Overall survival } \\
(\%)\end{array}$ \\
\hline
\end{tabular}

Intrahepatic cholangiocarcinoma ${ }^{a}$

Photon radiotherapy

SBRT/IMRT

$\begin{array}{llc}\text { Tse et al. [21] } & 2008 & 10 \\ \text { Ibarra et al. [22] } & 2012 & 11 \\ \text { Tao et al. } \text { [23] } & 2016 & 79^{\mathrm{b}} \\ \text { Shen et al. } \text { [24] } & 2017 & 28\end{array}$

Conventional RT

$\begin{array}{lll}\text { Zeng et al. [25] } & 2006 & 38 \\ & & 37 \\ \text { Chen et al. [26] } & 2010 & 35 \\ & & 49 \\ \text { Kim et al. }[27] & 2013 & 25 \\ & & 67\end{array}$

$\begin{array}{cccccc}50 & 25 & 60 & 50.1^{\mathrm{g}} & 11.8^{\mathrm{g}} & \mathrm{NA} \\ \text { Non-EBRT } & - & - & 24.8^{\mathrm{g}} & 5.5^{\mathrm{g}} & \mathrm{NA} \\ 50 & 25 & 60 & 38.5^{\mathrm{g}} & 9.6^{\mathrm{g}} & 9.5^{\mathrm{g}} \\ \text { Non-EBRT } & - & - & 16.4^{\mathrm{g}} & 4.9^{\mathrm{g}} & 5.1^{\mathrm{g}} \\ 44.7(\mathrm{CCRT}) & 2-3 \mathrm{~Gy} / \mathrm{fr} . & 54^{\mathrm{d}} & 30.4^{\mathrm{g}} & \mathrm{NA} & 9.3^{\mathrm{g}} \\ \text { Chemotherapy } & - & - & 22.4^{\mathrm{g}} & \mathrm{NA} & 6.2^{\mathrm{g}}\end{array}$

Proton radiotherapy

Ohkawa et al. [28] $2015 \quad 12^{\mathrm{c}}$

$\begin{array}{cccccc}72.6 & 22 & 97 & 82^{\mathrm{f}} & 61^{\mathrm{f}} & 27.5^{\mathrm{f}} \\ 58 & 15 & 80 & 69.7^{\mathrm{f}} & 46.5^{\mathrm{f}} & 22.5^{\mathrm{f}}\end{array}$

Carbon-ion radiotherapy

$\begin{array}{lll}\text { Hong et al. [29] } & 2016 & 39\end{array}$

36
30
58
45

$$
\text { (present study) }
$$

27

76

20

$\begin{array}{llll}105 & 77.8^{\mathrm{f}} \quad 53.4^{\mathrm{f}} \quad 23.8^{\mathrm{f}}\end{array}$

Perihilar cholangiocarcinoma

Photon radiotherapy

SBRT

$\begin{array}{lcccccccc}\text { Momm et al. }[7] & 2010 & 13 & 48 & 4 & 106 & \text { NA } & \text { NA } & 23.6^{\mathrm{g}} \\ \text { Kopek et al. }[16] & 2010 & 27^{\mathrm{h}} & 45 & 3 & 112 & \text { NA } & \text { NA } & 10.6^{\mathrm{f}} \\ \text { Polistina } \text { et al. }[8] & 2011 & 10 & 30 & 3 & 60 & \text { NA } & 80^{\mathrm{g}} & 35.5^{\mathrm{g}}\end{array}$

Conventional X-ray RT \pm brachytherapy \pm chemotherapy

\begin{tabular}{|c|c|c|c|c|c|c|c|c|}
\hline Ghafoori et al. [30] & 2011 & $37^{\mathrm{i}}$ & 45 & $1.8-3 \mathrm{~Gy} / \mathrm{fr}$ & NA & $59^{f}$ & $22^{\mathrm{f}}$ & $14^{\mathrm{f}}$ \\
\hline \multirow[t]{2}{*}{ Chen et al. [6] } & 2015 & 16 & 54 (CCRT) & \multirow{2}{*}{$1.8-2 \mathrm{~Gy} / \mathrm{fr}$} & \multirow{2}{*}{$65^{\mathrm{d}}$} & \multirow{2}{*}{$41^{\mathrm{f}}$} & NA & $13.5^{\mathrm{f}}$ \\
\hline & & 18 & 54 (RT alone) & & & & NA & $6.7^{\mathrm{f}}$ \\
\hline
\end{tabular}

Carbon-ion radiotherapy

(present study)

$2019 \quad 29 \quad 76$

20

$105 \quad 63.5^{\mathrm{f}} \quad 27.3^{\mathrm{f}}$

$12.6^{\mathrm{f}}$

${ }^{a}$ According to differences in the definition of intrahepatic cholangiocarcinoma, some cases of perihilar cholangiocarcinoma may be included among these studies.

${ }^{b}$ Various radiotherapy modalities such as proton radiotherapy, IMRT, conventional radiotherapy were included.

${ }^{\mathrm{c}}$ Curative treatment number

${ }^{\mathrm{d}}$ Calculated according to $2 \mathrm{~Gy} /$ fraction

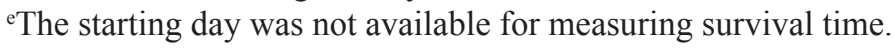

fSurvival time was measured from the start of radiotherapy

gSurvival time was measured from the time of diagnosis.

${ }^{\mathrm{h}}$ One case of intrahepatic cholangiocarcinoma was included in this study.

iSix patients were performed brachytherapy only.

Abbreviations: Gy: gray; RBE: relative biological effectiveness; BED: biological effective dose; MST: median survival time; NA: not available; RT: radiotherapy; SBRT: stereotactic body radiotherapy; IMRT: intensity modulated radiotherapy; EBRT: external beam radiotherapy; CCRT: concurrent chemoradiotherapy; fr.: fraction. 
than cholangiocarcinoma, 6) a hepatic disorder classified as Child-Pugh class A or B, 7) age $\geq 20$ years, 8) a performance status of 0 to 2 on the Eastern Cooperative Oncology Group scale, and 9) ability to understand and sign an informed consent form at each institution.

The exclusion criteria for this study were as follows: 1) previous treatment of the target tumor by other radiation therapies or surgery, 2) tumor invasion of the digestive tract, 3) untreatable ascites, 4) active malignant tumors other than the cholangiocarcinoma to be treated, 5) severe comorbidities such as uncontrolled diabetes mellitus, renal failure, or cardiac failure, and 6) a serious medical or psychological condition precluding safe administration of treatment.

Of the 75 patients treated with CIRT at the four institutions, 19 did not meet the eligibility criteria for this study for the following reasons: previous surgical treatment of the cholangiocarcinoma $(n=7)$, diagnosis by imaging without elevated tumor marker (CA19-9 or CEA) levels $(n=5)$, presence of metastasis to other organs $(n=3)$, presence of another active cancer $(n=2)$, Child-Pugh class C $(n=1)$, and no measurable lesion $(n=1)$. The remaining 56 patients were included in this study.

\section{Treatment}

The CIRT doses were calculated by multiplying the absorbed dose of the carbon ions by the RBE. The RBE value of carbon ions was assumed to be 3 at the distal part of the spread-out Bragg peak. Carbon-ion beams were controlled using with a pair of wobbler magnets, beam scatterers, ridge filters, a range shifter, multi-leaf collimators, and a range compensator [11].

The margin of the clinical target volume was established as $10 \mathrm{~mm}$ from the tumor. The planning target volume was determined by adding an additional margin of $5-10 \mathrm{~mm}$. If the tumors was too close to organs such as the gastrointestinal (GI) tract, these margins were reduced to avoid over-irradiation of organs at risk. The exact margin was decided on a case-by-case basis by the treating physician.

Dose prescriptions were selected according to the proximity of the tumor to the GI tract. At three of the four institutions, 52.8 Gy (RBE) and 60.0 Gy (RBE) were routinely administered via 4 -fraction CIRT. If the tumor is close to the GI tract, 12-fraction CIRT is used. At the fourth institutions, a dose of $76 \mathrm{~Gy}(\mathrm{RBE}) / 20$ fractions or 60 Gy $(\mathrm{RBE}) / 10$ fractions is prescribed in normal cases, while a dose of 70.2 Gy (RBE)/26 fractions, 65 Gy (RBE)/26 fractions, or $64.8 \mathrm{~Gy}(\mathrm{RBE}) / 25$ fractions were prescribed in cases in which the tumor was close to the GI tract. On the other hand, neither tumor size nor liver function was considered in determining the dose prescription.

Patient-machine alignment was achieved by overlapping the onboard image, taken in a daily vertical/horizontal position using a $\mathrm{kV}$ X-ray, with the reconstructed two-dimentional image taken during planning CT. Deviations in the skeletal anatomy, diaphragm, and implantation of fiducial markers were minimized between the two images. Respiratory gating at the end of the exhalation phase was used for CT planning, verification of the position on the treatment board, and irradiation [18]. Written informed consent was obtained from all enrolled patients.

\section{Evaluation}

PHC is defined as cholangiocarcinoma located in any of the right, left or common hepatic duct. IHC is defined as cholangiocarcinoma located peripheral to the secondary bifurcation of the right and/or left hepatic duct. LC was defined as no evidence of tumor regrowth within the planning target volume. The LC time was defined as the interval between the start of CIRT and local failure diagnosis or the last follow-up. Progression free was defined as neither evidence of tumor regrowth nor other recurrence. Survival time was calculated as the interval between the start of CIRT and death or the last follow-up. Death from hepatic failure related to CIRT was defined as death caused by deterioration of liver function without progression of the cholangiocarcinoma and without symptoms such as cholangitis or biliary stricture. In normal tissues, adverse events were classified according to the National Cancer Institute Common Terminology Criteria for Adverse Events, version 4.0 [19].

\section{Statistical analyses}

The OS, LC, and PFS rates were evaluated using the Kaplan-Meier method. For univariate analyses, log-rank tests were used to compare OS, LC, and PFS between subgroups. All factors with a $p$-value $<0.1$ in the univariate analysis were included in a multivariate analysis using the Cox proportional hazards model. Tumor site (IHC or PHC) was excluded from the prognostic factor analysis because these two types of cholangiocarcinoma are inherently different. Proportions were compared using the chi-square test or Fisher's exact test. The equality of population medians between cohorts was evaluated using the Mann-Whitney U test. The optimal cutoff values for the BED10, based on the maximum Youden index [20], for predicting local failure and severe adverse events were determined to be 105 and $89 \mathrm{~Gy}$, respectively, by receiver operating characteristics analysis. A $p$-value $<0.05$ was considered to represent significance. All statistical analyses were performed using SPSS software (version 20.0; IBM Japan, Ltd, Tokyo, Japan).

\section{Abbreviations}

BED: biological effective dose; CIRT: carbon-ion radiotherapy; IHC: intrahepatic cholangiocarcinoma; GI: 
gastrointesitinal; J-CROS: Japan Carbon-Ion Radiation Oncology Study Group; LC: local control; MST: median survival time; OS: overall survival; PFS: progressionfree survival; PHC: perihilar cholangiocarcinoma; RBE: relative biological effectiveness; SBRT: stereotactic radiotherapy.

\section{Author contributions}

Goro Kasuya, Kazuki Terashima, Kei Shibuya, and Shingo Toyama designed the study, assembled the data, performed the statistical analyses and interpretation, and wrote the manuscript. Hiroshi Tsuji, Daniel K. Ebner, Tomoaki Okimoto, Yoshiyuki Shioyama, Tatsuya Ohno, and Takashi Nakano interpreted the data and wrote the manuscript. Tadashi Kamada treated the patients and helped revise the manuscript. All authors read and approved the final manuscript.

\section{ACKNOWLEDGMENTS}

We wish to express our deep appreciation to the members of the JCROS.

\section{CONFLICTS OF INTEREST}

There are no conflicts of interest pertaining to this work for any of the authors.

\section{FUNDING}

No funding agency played a role in the study design, article writing, or data analysis.

\section{REFERENCES}

1. Khan SA, Davidson BR, Goldin R, Pereira SP, Rosenberg WM, Taylor-Robinson SD, Thillainayagam AV, Thomas HC, Thursz MR, Wasan H, and British Society of Gastroenterology. Guidelines for the diagnosis and treatment of cholangiocarcinoma: consensus document. Gut. 2002; 51:VI1-9. https://doi.org/10.1136/gut.51. suppl_6.vil. [PubMed]

2. Patel T. Cholangiocarcinoma-controversies and challenges. Nat Rev Gastroenterol Hepatol. 2011; 8:189200. https://doi.org/10.1038/nrgastro.2011.20. [PubMed]

3. Valle J, Wasan H, Palmer DH, Cunningham D, Anthoney A, Maraveyas A, Madhusudan S, Iveson T, Hughes S, Pereira SP, Roughton M, Bridgewater J, and ABC-02 Trial Investigators. Cisplatin plus gemcitabine versus gemcitabine for biliary tract cancer. N Engl J Med. 2010; 362:1273-81. https://doi.org/10.1056/NEJMoa0908721. [PubMed]

4. Okusaka T, Nakachi K, Fukutomi A, Mizuno N, Ohkawa S, Funakoshi A, Nagino M, Kondo S, Nagaoka S, Funai
J, Koshiji M, Nambu Y, Furuse J, et al. Gemcitabine alone or in combination with cisplatin in patients with biliary tract cancer: a comparative multicentre study in Japan. Br J Cancer. 2010; 103:469-74. https://doi.org/10.1038/ sj.bjc.6605779. [PubMed]

5. Anderson CD, Pinson CW, Berlin J, Chari RS. Diagnosis and treatment of cholangiocarcinoma. Oncologist. 2004; 9:43-57. https://doi.org/10.1634/theoncologist.9-1-43. [PubMed]

6. Chen SC, Chen MH, Li CP, Chen MH, Chang PM, Liu CY, Tzeng $\mathrm{CH}$, Liu YM, Yen SH, Chao Y, Huang PI. External beam radiation therapy with or without concurrent chemotherapy for patients with unresectable locally advanced hilar cholangiocarcinoma. Hepatogastroenterology. 2015; 62:102-07. [PubMed]

7. Momm F, Schubert E, Henne K, Hodapp N, Frommhold H, Harder J, Grosu AL, Becker G. Stereotactic fractionated radiotherapy for Klatskin tumours. Radiother Oncol. 2010; 95:99-102. https://doi.org/10.1016/j.radonc.2010.03.013. [PubMed]

8. Polistina FA, Guglielmi R, Baiocchi C, Francescon P, Scalchi P, Febbraro A, Costantin G, Ambrosino G. Chemoradiation treatment with gemcitabine plus stereotactic body radiotherapy for unresectable, nonmetastatic, locally advanced hilar cholangiocarcinoma. Results of a five year experience. Radiother Oncol. 2011; 99:120-23. https://doi.org/10.1016/j.radonc.2011.05.016. [PubMed]

9. Lee J, Yoon WS, Koom WS, Rim CH. Efficacy of stereotactic body radiotherapy for unresectable or recurrent cholangiocarcinoma: a meta-analysis and systematic review. Strahlenther Onkol. 2019; 195:93-102. https://doi. org/10.1007/s00066-018-1367-2. [PubMed]

10. Kanai T, Furusawa Y, Fukutsu K, Itsukaichi H, Eguchi-Kasai $\mathrm{K}$, Ohara H. Irradiation of mixed beam and design of spreadout Bragg peak for heavy-ion radiotherapy. Radiat Res. 1997; 147:78-85. https://doi.org/10.2307/3579446. [PubMed]

11. Kanai T, Matsufuji N, Miyamoto T, Mizoe J, Kamada T, Tsuji H, Kato H, Baba M, Tsujii H. Examination of GyE system for HIMAC carbon therapy. Int J Radiat Oncol Biol Phys. 2006; 64:650-56. https://doi.org/10.1016/j. ijrobp.2005.09.043. [PubMed]

12. Ebner DK, Kamada T. The emerging role of carbonion radiotherapy. Front Oncol. 2016; 6:140. https://doi. org/10.3389/fonc.2016.00140. [PubMed]

13. Abe T, Shibuya K, Koyama Y, Okamoto M, Kiyohara H, Katoh H, Shimada H, Kuwano H, Ohno T, Nakano T. Initial results of hypofractionated carbon ion radiotherapy for cholangiocarcinoma. Anticancer Res. 2016; 36:2955-60. [PubMed]

14. Kasuya G, Kato H, Yasuda S, Tsuji H, Yamada S, Haruyama Y, Kobashi G, Ebner DK, Okada NN, Makishima H, Miyazaki M, Kamada T, Tsujii H, and Liver Cancer Working Group. Progressive hypofractionated carbon-ion 
radiotherapy for hepatocellular carcinoma: combined analyses of 2 prospective trials. Cancer. 2017; 123:3955-65. https://doi.org/10.1002/cncr.30816. [PubMed]

15. Bi AH, Zeng ZC, Ji Y, Zeng HY, Xu C, Tang ZY, Fan J, Zhou J, Zeng MS, Tan YS. Impact factors for microinvasion in intrahepatic cholangiocarcinoma: a possible system for defining clinical target volume. Int $\mathrm{J}$ Radiat Oncol Biol Phys. 2010; 78:1427-36. https://doi.org/10.1016/j. ijrobp.2009.09.069. [PubMed]

16. Kopek N, Holt MI, Hansen AT, Høyer M. Stereotactic body radiotherapy for unresectable cholangiocarcinoma. Radiother Oncol. 2010; 94:47-52. https://doi.org/10.1016/j. radonc.2009.11.004. [PubMed]

17. World Medical Association Declaration of Helsinki: ethical principles for medical research involving human subjects. JAMA. 2000; 284:3043-45. https://doi.org/10.1001/ jama.284.23.3043. [PubMed]

18. Minohara S, Kanai $\mathrm{T}$, Endo M, Noda K, Kanazawa M. Respiratory gated irradiation system for heavy-ion radiotherapy. Int J Radiat Oncol Biol Phys. 2000; 47:1097103. https://doi.org/10.1016/S0360-3016(00)00524-1. [PubMed]

19. National Cancer Institute. Common Terminology Criteria for Adverse Events (CTCAE) version 4.0 2010. Available from URL: https://www.eortc.be/services/doc/ctc/ CTCAE 4.03 2010-06-14 QuickReference 5x7.pdf.

20. Youden WJ. Index for rating diagnostic tests. Cancer. 1950; 3:32-35. $\quad$ https://doi.org/10.1002/10970142(1950)3:1<32::AID-CNCR2820030106>3.0.CO;2-3. [PubMed]

21. Tse RV, Hawkins M, Lockwood G, Kim JJ, Cummings B, Knox J, Sherman M, Dawson LA. Phase I study of individualized stereotactic body radiotherapy for hepatocellular carcinoma and intrahepatic cholangiocarcinoma. J Clin Oncol. 2008; 26:657-64. https://doi.org/10.1200/JCO.2007.14.3529. [PubMed]

22. Ibarra RA, Rojas D, Snyder L, Yao M, Fabien J, Milano M, Katz A, Goodman K, Stephans K, El-Gazzaz G, Aucejo F, Miller C, Fung J, et al. Multicenter results of stereotactic body radiotherapy (SBRT) for non-resectable primary liver tumors. Acta Oncol. 2012; 51:575-83. https://doi.org/10.31 09/0284186X.2011.652736. [PubMed]

23. Tao R, Krishnan S, Bhosale PR, Javle MM, Aloia TA, Shroff RT, Kaseb AO, Bishop AJ, Swanick CW, Koay EJ, Thames HD, Hong TS, Das P, Crane CH. Ablative radiotherapy doses lead to a substantial prolongation of survival in patients with inoperable intrahepatic cholangiocarcinoma: a retrospective dose response analysis. J Clin Oncol. 2016; 34:219-26. https://doi.org/10.1200/JCO.2015.61.3778. [PubMed]

24. Shen ZT, Zhou H, Li AM, Li B, Shen JS, Zhu XX. Clinical outcomes and prognostic factors of stereotactic body radiation therapy for intrahepatic cholangiocarcinoma. Oncotarget. 2017; 8:93541-50. https://doi.org/10.18632/ oncotarget.19972. [PubMed]

25. Zeng ZC, Tang ZY, Fan J, Zhou J, Qin LX, Ye SL, Sun HC, Wang BL, Li D, Wang JH, Zeng MS, Guo W, Tan YS. Consideration of the role of radiotherapy for unresectable intrahepatic cholangiocarcinoma: a retrospective analysis of 75 patients. Cancer J. 2006; 12:113-22. [PubMed]

26. Chen YX, Zeng ZC, Tang ZY, Fan J, Zhou J, Jiang W, Zeng MS, Tan YS. Determining the role of external beam radiotherapy in unresectable intrahepatic cholangiocarcinoma: a retrospective analysis of 84 patients. BMC Cancer. 2010; 10:492. https://doi.org/10.1186/14712407-10-492. [PubMed]

27. Kim YI, Park JW, Kim BH, Woo SM, Kim TH, Koh YH, Lee WJ, Kim CM. Outcomes of concurrent chemoradiotherapy versus chemotherapy alone for advanced-stage unresectable intrahepatic cholangiocarcinoma. Radiat Oncol. 2013; 8:292. https://doi.org/10.1186/1748-717X-8-292. [PubMed]

28. Ohkawa A, Mizumoto M, Ishikawa H, Abei M, Fukuda K, Hashimoto T, Sakae T, Tsuboi K, Okumura T, Sakurai H. Proton beam therapy for unresectable intrahepatic cholangiocarcinoma. J Gastroenterol Hepatol. 2015; 30:957-63. https://doi.org/10.1111/jgh.12843. [PubMed]

29. Hong TS, Wo JY, Yeap BY, Ben-Josef E, McDonnell EI, Blaszkowsky LS, Kwak EL, Allen JN, Clark JW, Goyal L, Murphy JE, Javle MM, Wolfgang JA, et al. Multiinstitutional phase II study of high-dose hypofractionated proton beam therapy in patients with localized, unresectable hepatocellular carcinoma and intrahepatic cholangiocarcinoma. J Clin Oncol. 2016; 34:460-68. https://doi.org/10.1200/JCO.2015.64.2710. [PubMed]

30. Ghafoori AP, Nelson JW, Willett CG, Chino J, Tyler DS, Hurwitz HI, Uronis HE, Morse MA, Clough RW, Czito BG. Radiotherapy in the treatment of patients with unresectable extrahepatic cholangiocarcinoma. Int $\mathrm{J}$ Radiat Oncol Biol Phys. 2011; 81:654-59. https://doi.org/10.1016/j. ijrobp.2010.06.018. [PubMed] 